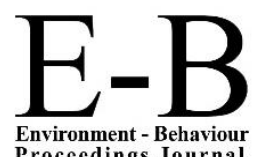

Procecdings Journal
AIVCE-BS-2, 2020ShahAlam

https://www.amerabra.org; https://fspu.uitm.edu.my/cebs; https://www.emasemasresources.com/ AMEABRA International Virtual Conference on Environment-Bahaviour Studies, $2^{\text {nd }}$ Series CE-Bs, FSPU, Universiti Teknologi MARA, Shah Alam, 02-03 Dec 2020

\section{e-IPH}

e-International Publishing House Ltd. United Kingdom

\title{
Usage of Cosmetic Remover and Dry Eye Symptoms
}

\author{
Fatin Nur Najwa Norazman, Nurul Aqilah Anuar \\ Centre of Optometry Studies, Faculty of Health Sciences, \\ Universiti Teknologi MARA Cawangan Selangor, Kampus Puncak Alam, 42300 Selangor, Malaysia \\ fatin161@uitm.edu.my, ila.aqilah@gmail.com, fathirahr@gmail.com, shazain@uitm.edu.my \\ +60332584418
}

\begin{abstract}
Eye cosmetics are the contributing factors of dry eye, yet the effectiveness of cosmetic remover usage to reduce this problem is unknown. This study aimed to investigate the effect of regular use of cosmetic remover on dry eye symptoms. An online questionnaire consisting of 23 questions regarding dry eye symptoms and the frequency of cosmetic removal usage was distributed. Eighty-five female respondents answered the questionnaire, with the majority $(74.1 \%)$ reported used more than three types of cosmetic remover products. There was no significant difference in dry eye symptoms between regular and light cosmetic remover users $(p=0.83)$.
\end{abstract}

Keywords: cosmetic ; dry eye ; ocular discomfort

eISSN: 2398-4287@ 2020. The Authors. Published for AMER ABRA cE-Bs by e-International Publishing House, Ltd., UK. This is an open access article under the CC BYNC-ND license (http://creativecommons.org/licenses/by-nc-nd/4.0). Peer-review under responsibility of AMER (Association of Malaysian Environment-Behaviour Researchers), ABRA (Association of Behavioural Researchers on Asians) and cE-Bs (Centre for Environment-Behaviour Studies), Faculty of Architecture, Planning \& Surveying, Universiti Teknologi MARA, Malaysia.

DOI: https://doi.org/10.21834/ebpj.v5i15.2493.

\subsection{Introduction}

Evidence has shown that about 5 to 50 percent of the world's population suffers from dry eye disease, with a higher percentage reported among women than men (Stapleton et al., 2017; Farrand et al., 2017). Dry eye disease or keratoconjunctivitis sicca is a condition when the eyes do not produce enough tears or instability of the tear layer that causes the tears to evaporate quickly. Patients with dry eye problems often complain of discomfort on the ocular surface, which can lead to various other problems. This condition will indirectly affect their quality of life. A large number of people suffering from dry eye disease may experience symptoms such as burning sensation, sandy eyes, watery eyes, and temporary blurred vision (Zeev, Miller, \& Latkany, 2014). This blurred vision symptom is associated with uneven distribution of tears on the ocular surface, causing light entering the eye not to be focused. Patients with blurred vision symptoms are also more likely to report symptoms such as eye fatigue or eyestrain due to eye muscles having to work harder to focus on the images (Nichols, 2006). In addition to the symptoms mentioned above, itchy eyes and red eyes are also commonly reported symptom among dry eye patients.

It is known that the use of cosmetic products, mainly eye cosmetics, is often associated with contributing factors of dry eye symptoms and ocular discomfort among cosmetic wearers (Wang \& Craig, 2018). Cosmetic wearers experienced these dry eye symptoms due to clogging of the meibomian gland orifices because of the accumulation of cosmetic particles into the meibomian gland openings. The obstruction of meibomian glands will, in turn, disrupts the component of lipid production in the tear film. The reduction of lipid layers in the tear film eventually causes faster evaporation of the tear film (Sabeti et al., 2019). Therefore, eye care practitioners recommended proper cosmetic removal practice to their patients as one of dry eye management. It is also recommended for eye cosmetics wearers to use gentle eye scrub after removing the eye's cosmetics. However, the effectiveness of cosmetic remover use in reducing the risk of

eISSN: 2398-4287C 2020. The Authors. Published for AMER ABRA cE-Bs by e-International Publishing House, Ltd., UK. This is an open access article under the CC BYNC-ND license (http://creativecommons.org/licenses/by-nc-nd/4.0/). Peer-review under responsibility of AMER (Association of Malaysian Environment-Behaviour Researchers), ABRA (Association of Behavioural Researchers on Asians) and cE-Bs (Centre for Environment-Behaviour Studies), Faculty of Architecture, Planning \& Surveying, Universiti Teknologi MARA, Malaysia.

DOI: https://doi.org/10.21834/ebpj.v5i15.2493. 
dry eye symptoms is unknown. Therefore, this study was done to understand the effect of cosmetic remover usage on symptoms of dry eye among cosmetic wearers.

\subsection{Literature Review}

Women usually use cosmetic products to enhance their appearance, look presentable or professional, and boost their self-confidence. Among commonly used eye cosmetics by women are mascara, eyeliner, eyeshadow, and false lashes (Maroof et al., 2019). Besides that, primer, foundation, and concealer used around the eye area are also considered as eye cosmetics ( $\mathrm{Ng}$ et al., 2012). Studies found that meibomian gland blockage may happen due to eyeliner application within the lid margin, also known as "inside liner," or due to a mixture of cosmetics with sweat and tears (Okura et al., 2015; Ng et al., 2012). Furthermore, eye cosmetics usage frequently causes faster tear break-up time, which is a presentation of dry eye problems (Tsubota, 2018).

Thus, eye cosmetics removal is an essential procedure to reduce the risk of dry eye and meibomian gland dysfunction (MGD). The most effective way to remove cosmetics is by using oil-based cosmetic remover or a micelle-based cleansing product such as micellar water and performing lid hygiene (Ng et al., 2016). However, Okura et al. (2015) reported that oil-based cosmetic remover increases the risk of MGD and causes eye discomfort, hence suggested lid hygiene as the best way to manage MGD. It can be done by applying warm compression to the eyelid, followed by massaging the eyelids gently before cleaning the eyelid. This procedure will help unblock the meibomian gland orifices and reduce the risk of MGD among eye cosmetics wearers. Another study by Okura et al. (2015) investigated the effects of Eye Shampoo (MediProduct Co., Ltd., Tokyo, Japan) in the cosmetic removal routine and found that the tear break-up time is longer in subjects that use Eye Shampoo to remove their cosmetics. Their symptoms, meibomian orifices, and meibomian secretion are also better.

The above studies suggested that proper lid hygiene during cosmetic removal routine could reduce the risk of developing dry eyes. Even so, no study was done to find out the best type of cosmetic remover product that can help to reduce the risk of developing dry eyes. This study investigated the effect of cosmetic removal products on dry eye symptoms. We compared the severity of dry eye symptoms in regular and light cosmetic remover users and determined the type of cosmetic remover associated with the lowest severity of eye dry eye symptoms.

\subsection{Methodology}

\subsection{Study Materials}

This cross-sectional study was adopted and revised from work done by $\mathrm{Ng}$ et al. (2012) that investigated eye cosmetics usage and its relationship with ocular comfort. The authors modified several items in the original questionnaire to suit the study needs. Six eye care professionals validated it, followed by a pilot test on another six non-eye care professionals to ensure the questions' adequacy. All respondents involved in the pilot test were not included as study participants and not counted in the data analysis to avoid bias in the result.

The final survey of 23 questions included in this questionnaire was divided into four sections. The first eight questions collected respondents' demographic data, followed by the Ocular Surface Disease Index (OSDI) questionnaire, type and frequency of cosmetic usage, and the last two items on cosmetic removal routine. Each item on the OSDI questionnaire was graded using a rating scale from zero to four, which zero is none of the time, one is some of the time, two is half of the time, three is most of the time, and four is all of the time. The total OSDI score was then calculated and classified according to the severity of dry eye symptoms. A higher OSDI score indicated a higher severity of dry eye symptoms, which 0 to 12 points can be label as normal, 13 to 22 points as mild, 23 to 32 points as moderate, and 33 to 100 points as severe (Walt, 2004). Meanwhile, the frequency of eye cosmetic usage and removal routine was graded based on the average number of days the product is used per week.

The frequency of cosmetic removal product used was categorized into two, regular usage and light usage. Regular cosmetic removal product use was defined as using three and more days per week, while light usage was using cosmetic removal product of fewer than three days per week.

\subsection{Study Procedure}

The questionnaires were administered to full-time undergraduate female students from the Faculty of Health Sciences UiTM Puncak Alam Campus via Google Form. Each class representative from each course was given the Google Form link and was asked to share it with their classmates. However, only respondents that fulfilled the inclusion criteria were included in this study. The inclusion criteria were cosmetic users and non-contact lens wearer. This study obtained ethics approval from the UiTM Research Ethics Committee priorly.

\subsection{Data analysis}

Data from the online questionnaire was downloaded into a Microsoft Excel worksheet and analyzed using Statistical Package for the Social Sciences (SPSS) Version 20.0. Only completed questionnaires were included in the data analysis. The normality of data was tested using the Shapiro-Wilk test. Then, descriptive statistics were computed. The independent sample t-test was used to compare the OSDI score between regular and light cosmetic remover users, followed by multiple linear regression analysis to predict the type of 
cosmetic remover that causes the lowest dry eye severity. The $p$-values less than 0.05 was considered significant for all statistical test. The analyzed data are presented as mean and standard deviation (SD).

\subsection{Findings}

\subsection{Demographic Data}

A total of 122 respondents completed the questionnaires in this study. Out of all these respondents, one was male, four were non-health science students, four were contact lens wearers who wore less than two weeks, and 28 were non-cosmetic wearers. They were excluded from the data analysis, leaving a total of 85 female respondents with a mean age of $22.87(S D=1.19)$ for scrutinization. This study's respondents ranged from 20 to 25 years, with respondents aged 23 years as the highest group $(52.9 \%)$. More than half of the respondents are in their fourth year of study $(n=44)$, followed by third-year $(n=25)$, second-year $(n=9)$, and first-year $(n=7)$. Based on the Shapiro-Wilk test, the dependent data were normally distributed with $p=0.20$.

\subsection{Ocular Surface Disease Index (OSDI) Score}

This study's mean OSDI score was 24.69 ( $S D=1.67$ ), with the OSDI scores ranged between 0 and 64 . Based on the OSDI classification of severity of dry eye, only 22 respondents $(24.7 \%)$ have a normal ocular surface, while the others reported having dry eye symptoms. Eighteen (21.2\%) have mild symptoms, $22(25.9 \%)$ have moderate symptoms, and $24(28.2 \%)$ have severe symptoms of dry eye (Figure 1). More than one-third of the respondents scored more than 15 points $(74.1 \%)$, which was the cut off point for symptomatic dry eye according to OSDI scores guideline (Schiffman et al., 2003). It was interesting to note that $27(31.8 \%)$ of the respondents reported they used eye drops to make their eyes feel comfortable. The cosmetics remover users' data was further explored to find the differences in OSDI scores between regular cosmetics remover users and light cosmetics remover users.

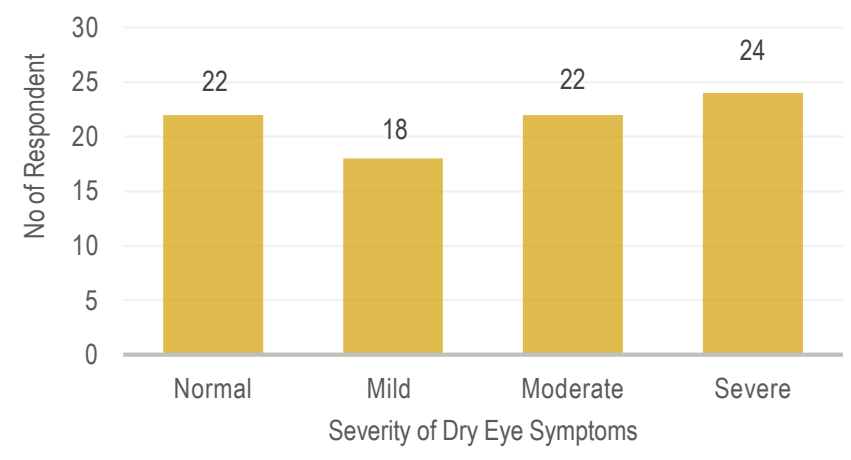

Fig. 1: Severity of dry eye based on OSDI classification

\subsection{Cosmetic Remover Usage}

All 85 respondents included in this study reported using at least one type of eye cosmetics. Forty-one (48.2\%) of the respondents stated using eye cosmetics at least three times per week, but only $21(24.7 \%)$ regularly employ three or more types of eye cosmetics.

When asked about the usage of cosmetics remover products per week, only nine responded they use cosmetics remover less than three times per week. The majority of the respondents $(90.6 \%)$ also claimed they paid attention when removing their cosmetics. The use of only one type of cosmetics remover was rare $(3.5 \%)$, and most of the respondents used three or more cosmetics remover products (74.1\%). Fifty-eight of them also confessed they utilized three or more types of cosmetic remover products regularly. The two most used cosmetics remover products were facial cleanser $(100 \%)$ and micellar water $(76.5 \%)$, while the least used cosmetics remover was lid scrub (36.5\%), as shown in Figure 2.

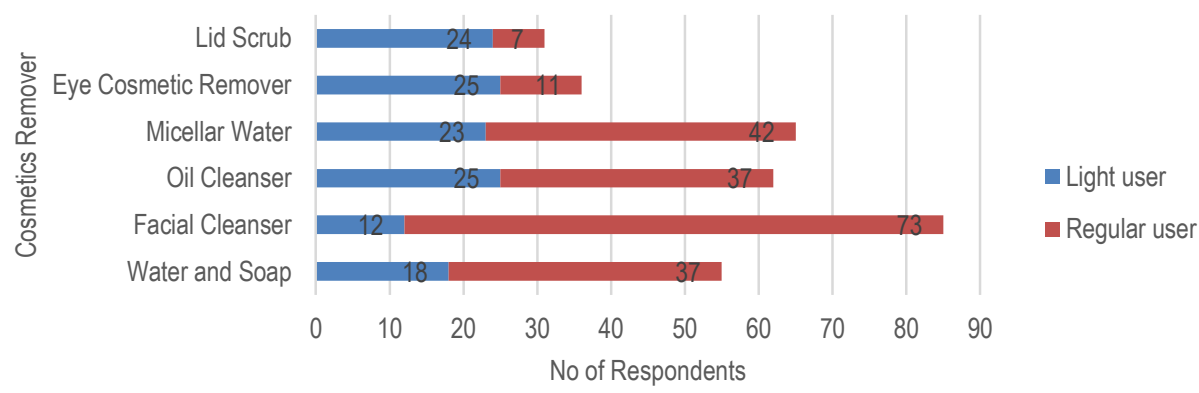

Fig. 2: Pattern of cosmetic remover products usage between light and regular users 


\subsection{Effect of Cosmetic Remover Usage on Dry Eye Symptoms}

There was an insignificant $(t(83)=0.93, p=0.35)$ higher pattern of OSDI score among respondents who did not pay attention during the cosmetics removal routine $(M=29.53, S D=16.14)$ compared to those who pay attention when removing cosmetics $(M=24.19, S D=15.37)$. However, regular cosmetics remover users showed a higher severity of dry eye symptoms $(M=24.82, S D=15.06)$ than light cosmetics remover users $(M=23.65, S D=19.26)$. Thus, it was not significant. There was no statistical difference in the OSDI score between regular and light users for all cosmetics remover types except for lid scrub, $t(29)=2.25, p=0.03$ (Table 1).

Table 1. Comparison of OSDI scores between regular and light cosmetics remover usage

\begin{tabular}{|c|c|c|c|c|c|c|}
\hline & Water and Soap & Facial Cleanser & Oil Cleanser & Micellar Water & $\begin{array}{l}\text { Eye Cosmetic } \\
\text { Remover }\end{array}$ & Lid Scrub \\
\hline \multicolumn{7}{|c|}{ Regular Users ( $\geq 3$ times a week) } \\
\hline $\mathrm{N}$ & 37 & 73 & 37 & 42 & 11 & 7 \\
\hline Mean OSDI (SD) & $29.11(15.26)$ & $24.91(14.96)$ & $22.71(16.76)$ & $23.85(15.72)$ & $20.63(16.33)$ & $16.45(10.18)$ \\
\hline \multicolumn{7}{|c|}{ Light Users ( $<3$ times a week) } \\
\hline $\mathrm{N}$ & 18 & 12 & 25 & 23 & 25 & 24 \\
\hline Mean OSDI (SD) & $26.99(16.36)$ & $23.36(18.72)$ & $27.77(14.02)$ & $28.01(15.04)$ & $28.54(14.88)$ & $29.92(14.74)$ \\
\hline Mean diff (95\% Cl) & $\begin{array}{l}-2.12 \\
(-11.12,6.89)\end{array}$ & $\begin{array}{l}-1.55 \\
(-11.16,8.06)\end{array}$ & $\begin{array}{l}5.06 \\
(-3.08,13.20)\end{array}$ & $\begin{array}{l}4.16 \\
(-3.87,12.19)\end{array}$ & $\begin{array}{l}7.91 \\
(-3.36,19.18)\end{array}$ & $\begin{array}{l}13.46 \\
(1.23,25.69)\end{array}$ \\
\hline t-stats (df) & $-0.47(53)$ & $-0.32(83)$ & $1.24(60)$ & $1.04(63)$ & $1.43(34)$ & $2.25(29)$ \\
\hline$p$-value & 0.64 & 0.75 & 0.22 & 0.30 & 0.16 & $0.03^{*}$ \\
\hline
\end{tabular}

* indicates significant difference at $p<0.05$

\subsection{Usage of Cosmetic Remover Causing the Lowest Severity of Dry Eye Symptoms.}

The data was further analyzed to determine the type of cosmetics remover usage that contributed to the highest severity of dry eye symptoms, as previously defined in the research objective. The lowest mean OSDI scores observed among cosmetics remover users using facial cleanser $(M=24.69, S D=15.42)$, followed by oil cleanser $(M=24.75, S D=15.79)$ and micellar water $(M=25.33, S D=15.49)$. $A$ multiple linear regression analysis was done to predict each cosmetics remover usage effect on the OSDI score. All types of cosmetic remover products in this study accounted for a $27 \%$ non-significant predictor of dry eye symptoms based on the OSDI score with $\mathrm{R}^{2}=0.27$, adjusted $\mathrm{R}^{2}=0.04, \mathrm{~F}(6,19)=1.19, p=0.35$. Unstandardized $(\mathrm{B})$ and standardized $(\beta)$ regression coefficients and $p$-value for each predictor in the regression model are reported in Table 2 . The only statistically significant factor that independently contributes to the severity of symptoms after adjustment for other cosmetic remover products was lid scrub $(p=0.03)$.

Table 2. Prediction of cosmetic remover usage on OSDI score

\begin{tabular}{lccc}
\hline & \multicolumn{2}{c}{ Coefficients } & \multirow{2}{*}{ p-value } \\
\cline { 2 - 3 } & $\mathbf{B}(\mathbf{9 5 \%} \mathbf{~ C l})$ & $\boldsymbol{\beta}$ & \\
\hline Water and soap & -2.53 & -0.09 & 0.74 \\
Facial cleanser & 4.99 & 0.15 & 0.57 \\
Oil cleanser & 17.41 & 0.56 & 0.08 \\
Micellar water & -11.35 & -0.36 & 0.27 \\
Eye cosmetic remover & -1.67 & -0.04 & 0.87 \\
Lid scrub & -25.48 & -0.55 & $0.03^{*}$ \\
\hline
\end{tabular}

\subsection{Discussion}

In general, our study reported the behavior of cosmetic wearers on their usage of cosmetic removers following cosmetics application. This information includes the prevalence of use for six types of cosmetic remover products and their frequency of use. Previous studies have documented that eye cosmetics can negatively affect the ocular surface (Coroneo et al., 2006; Ng et al., 2016; O'Dell, Sullivan, \& Periman, 2017). Therefore, eye cosmetics need to be removed appropriately to maintain ocular health. Although our study found that most respondents $(89.4 \%)$ regularly employ cosmetic removers, it was not significant to prove that regular usage of cosmetic removers reduces the risk of dry eye. When comparing the regular user of cosmetic remover and light user of cosmetic remover, there is no notable difference in the dry eye severity. All types of cosmetics remover products showed no statistical difference in the OSDI score except for lid scrub. The mean OSDI score among regular lid scrub users was lower compared to light users.

In this study, the usage of lid scrub was the most crucial factor contributing to the magnitude of dry eye symptoms. We found that lid scrub has the highest negative beta-coefficient value suggesting that it is the best type of cosmetic remover for lowering dry eye symptoms. The multiple regression analysis also indicated that other cosmetic remover products were not associated with our respondents' OSDI scores. There are several studies agreed that lid hygiene is the best method to manage meibomian gland dysfunction and dry eye (Okura et al., 2015; Epstein et al., 2015; Aryasit et al., 2020). Gentle eye scrub or lid hygiene can remove excess cosmetics that may be missed. Aside from that, cleansing the eyelid is beneficial for anterior blepharitis and reduces the risk of bacterial infection and meibomian gland dysfunction (Benitez-del-Castillo, 2012). Although previous studies did not compare the lid scrub usage with other cosmetic remover types, our study's results agree that lid scrub can reduce the dry eye symptoms and risk of meibomian gland 
dysfunction among cosmetics wearers. Lid scrub needs to be used in conjunction with different cosmetic remover types as lid scrub alone may not be adequate to remove cosmetics.

The double cleansing method is a popular method to cleanse the face from cosmetics and impurities. In the double cleansing method, two types of cosmetic remover are used, an oil-based cleanser, and a water-based cleanser (Sharkey, 2019). Nowadays, micellar water is frequently used for cosmetic removal and general cleansing (Day et al., 2017). Unlike plain water, micellar water contains micelles, which are oil-in-water suspensions that effectively remove dirt, cosmetics, and oil (Link \& Hatanaka, 2020). Our study respondents also chose facial cleanser, micellar water, and oil cleanser as the top three cosmetic remover products to remove their cosmetics.

We all know that most cosmetic products contain chemicals that could damage the ocular surface and cause ocular irritation, tear film instability, and dry eye disease (Wang \& Craig, 2018). Since our eyelid skin is delicate, it allows for the easy absorption of chemicals (O'Donoghue, 2000). The behavior among cosmetic wearers on the frequency of cosmetic remover usage could provide essential data in assessing chemical ingredients exposure in these products with the risk of dry eye. Regular usage of cosmetic products, including cosmetic remover, may cause accumulation of these chemical compounds and affect eye health. In our study, the majority of respondents reported using three or more cosmetics remover products. Therefore, the number of respondents associated with symptomatic dry eye disease was high.

Aside from that, from the multiple regression analysis, oil cleanser was the highest contributor to the OSDI score. There is a report that suggests oil-based cosmetic remover could increase the risk of MGD (Okura et al., 2015). Although oil-based cleanser effectively removes waterproof cosmetics ( $\mathrm{Ng}$ et al., 2016), the product itself might increase the risk of dry eye.

Considering our present study results, we recommend that eye care practitioners be aware of the cosmetic products that their patients use and their cosmetics removal routine. This knowledge will allow them to counsel patients on cosmetics' possible adverse effects on the ocular surface, especially for patients who may already suffer from ocular surface disease (O'Dell, Sullivan, \& Periman, 2017).

\subsection{Study Limitations}

This research, however, is subject to several limitations. One of the curbs of this study is the percentage of respondents that use more than three types of eye cosmetics regularly was only $27.1 \%$. Moreover, the data collection was done between April till May 2020, which was during the 2020 Malaysia Movement Control Order (MCO) due to the COVID-19 pandemic. It might be possible that most of the respondents did not use any cosmetics during that period as the Malaysian citizens were required to stay at home. These may cause the mean difference of OSDI score between regular and light cosmetic remover users to be insignificant.

Another limitation might come from the dry eye questionnaire used for this study. Even though the OSDI score was proven to be a reliable and valid tool to classify the severity of dry eye, it may not be the best tool in measuring ocular comfort among cosmetic wearers. The questions only address some of the ocular symptoms of dry eye, such as light sensitivity, grittiness, and pain, unlike other symptoms such as tearing and foreign body sensation. The lack in some of the components makes it less accurate for the respondents to note specific symptoms that the respondents may need to describe. By considering that the respondents' dry eye symptoms may be due to external or environmental factors, or the use of eye cosmetics alone, or a combination of both, a better questionnaire could be used in future studies.

\subsection{Conclusion \& Recommendations}

In summary, the results showed no significant difference in the regularity of cosmetics removal applications with the severity of dry eye. There was also no significant difference in the types of cosmetic removal products used by health science students, contributing to the severity level of dry eye, except for lid scrub. These findings may be due to the lack of components of the OSDI score, making it not comprehensive enough to detect ocular discomfort associated with cosmetic use. Plus, the respondents would only experience shortterm changes in dry eye symptoms when using eye cosmetics and their removal routine, thus, underestimating the overall results. With various cosmetics remover available in the market, further research is needed to assess the effects of frequent use of cosmetics products on the ocular surface and tear function, which may be underestimated.

\section{Acknowledgement}

We want to thank all respondents for participating in this study, and members of the Centre for Optometry Studies, Faculty of Health Sciences UiTM for their contribution to this study.

\section{Paper Contribution to Related Field of Study}

In general, our study reported the behavior of cosmetic wearers on their usage of cosmetic removers following cosmetics application. This information includes the prevalence of use for six types of cosmetic remover products and their frequency of use. Based on our findings, eye care practitioners must check on their patients' cosmetic usage routine and consider it before coming up with the treatment plan and management. 


\section{References}

Aryasit, O., Uthairat, Y., Singha, P., \& Horatanaruang, O. (2020). Efficacy of baby shampoo and commercial eyelid cleanser in patients with meibomian gland dysfunction: A randomized controlled trial. Medicine, 99(19), e20155. https://doi.org/10.1097/MD.0000000000020155

Benitez-del-Castillo, J. M. (2012). How to promote and preserve eyelid health. Clinical Ophthalmology, 6(1), 1689-1698. https://doi.org/10.2147/OPTH.S33133

Coroneo, M. T., Franzco, F., Rosenberg, M. L., \& Cheung, L. M. (2006). Ocular effects of cosmetic products and procedures. Ocular Surface, 4(2), 94-102. https://doi.org/10.1016/S1542-0124(12)70031-9

Day, K., Tazzioli, J., Liu, M., \& Hawkins, S. (2017). Sensitive skin compatibility of micellar water. Journal of the American Academy of Dermatology, 76(6), AB233. https://doi.org/10.1016/j.jaad.2017.04.904

Epstein, A., Pang, L., Najafi-Tagol, K., Najafi, R., Stroman, D., \& Debabov, D. (2015). Comparison of Bacterial Lipase Activity in the Presence of Eye Lid Cleansers. Invest. Ophthalmol. Vis. Sci., 56(7), 4446.

Farrand, K. F., Fridman, M., Stillman, I. Ö., \& Schaumberg, D. A. (2017). Prevalence of Diagnosed Dry Eye Disease in the United States Among Adults Aged 18 Years and Older. American journal of ophthalmology, 182, 90-98. https://doi.org/10.1016/j.ajo.2017.06.033

Link, R., \& Hatanaka, M. (2020). 5 Benefits and Uses of Micellar Water. Retrieved from Healthline website: https://www.healthline.com/nutrition/micellar-water-benefits

Maroof, S., Mehmood, H., Khurshied, S., Bukhari, S. K., Shabir, M. B., Malik, K., Shan, K., \& Zameer, U. (2019). Eye Makeup Use, Adoption of Makeup Safety Guidelines among Women and Its Association with Ocular Surface Disease Index (OSDI): Analytical Cross-Sectional Study. The International Journal of Frontier Sciences, 3(2), 7883. https://doi.org/10.37978/tijfs.v3i2.51

$\mathrm{Ng}$, A., Evans, K., North, R., \& Purslow, C. (2012). Eye cosmetic usage and associated ocular comfort. Ophthalmic and Physiological Optics, 32(6), 501-507. https://doi.org/10.1111/j.1475-1313.2012.00944.x

Ng, A., Evans, K., North, R. V., Lyndon, J., \& Purslow, C. (2016). Impact of Eye Cosmetics on the Eye, Adnexa, and Ocular Surface, Eye \& Contact Lens: Science \& Clinical Practice, 42(4), 211-220. https://doi.org/10.1097/ICL.0000000000000181

Nichols, K. K. (2006). Patient-reported symptoms in dry eye disease. Ocular Surface, 4(3), 137-145. https://doi.org/10.1016/S1542-0124(12)70040-X

Okura, M., Kawashima, M., Katagiri, M., Shirasawa, T., \& Tsubota, K. (2015). New eye cleansing product improves makeup-related ocular problems. Journal of Ophthalmology, 2015, 1-7. https://doi.org/10.1155/2015/831628

O'Dell, L. E., Sullivan, A. G., \& Periman, L. M. (2017). When beauty talk turns ugly. Adv. Ocular Care, 1, 16-20.

O'Donoghue, M. N. (2000). Eye cosmetics. Dermatol. Clin., 18(4), 633-639.

Sabeti, S., Kheirkhah, A., Yin, J., \& Dana, R. (2020). Management of Meibomian Gland Dysfunction: A Review. Survey of Ophthalmology, 65(2), $205-217$. https://doi.org/10.1016/j.survophthal.2019.08.007

Sharkey, L. (2019). A Beginner's Guide to Double Cleansing. Retrieved from Healthline website: https://www.healthline.com/health/beauty-skin-care/double-cleansing

Stapleton, F., Alves, M., Bunya, V. Y., Jalbert, I., Lekhanont, K., Malet, F., Na, K. S., Schaumberg, D., Uchino, M., Vehof, J., Viso, E., Vitale, S., \& Jones, L. (2017). TFOS DEWS II Epidemiology Report. The ocular surface, 15(3), 334-365. https://doi.org/10.1016/j.jtos.2017.05.003

Tsubota, K. (2018). Short tear film breakup time-type dry eye. Investigative Ophthalmology and Visual Science, 59(14), DES64-DES70. https://doi.org/10.1167/iovs.1723746

Walt, J. (2004). Ocular Surface Disease Index (OSDI) Administration and Scoring Manual. Allergan, Inc: Irvine, CA.

Wang, M. T. M., \& Craig, J. P. (2018). Investigating the effect of eye cosmetics on the tear film: Current insights. Clinical Optometry, 10 , 33-40. https://doi.org/10.2147/OPTO.S150926

Zeev, M. S. Ben, Miller, D. D., \& Latkany, R. (2014). Diagnosis of dry eye disease and emerging technologies. Clinical Ophthalmology, 8, 581-590. https://doi.org/10.2147/OPTH.S45444 